\title{
An Interpretation of Wordsworth's Poems from Psycho-Analysis
}

\author{
Mingxin $\mathrm{Li}^{1, *}$ \\ ${ }^{1}$ Henan Polytechnic University, China \& Kelaniya University, Sri Lanka \\ *Correspondence: Henan Polytechnic University, China \& Kelaniya University, Sri Lanka. E-mail: \\ Snowlily2008@yeah.net
}

Received: September 11, 2014 Accepted: November 10, 2014 Online Published: January 21, 2015

doi:10.5430/wjel.v5n1p8 URL: http://dx.doi.org/10.5430/wjel.v5n1p8

\begin{abstract}
During the past two decades scholars and researchers have studied a high degree of William Wordsworth poem and poetic theory from various angles. William Wordsworth as the founder of British Romantic poet occupies an important position in English literary history. His literary life, works and poetical theory in the later period of French Revolution had given rise to various issues; however, some critics labeled him as a passive romantic because of his residence in the Lake District, which influenced readers for a long time.

This paper positively analyses Wordsworth poems based on psycho-analysis theory to probe into the growth of the poet mind, laying stress on the deep motive force and the profound implication of the Returning Complex in Wordsworth's turning after the French Revolution. Soul as the focus of collective unconsciousness manifests itself in the primitive archetype. Soul presents itself in the Universe, in humankind and in nature. In the poet's eyes, returning to Self is to returning to soul.

In the light of Karl Jung's theory, also by the analysis of his poems, a conclusion can be drawn that Wordsworth is a more positive fighter and psychological poet than an escapist. He finds a returning way to soul.
\end{abstract}

Keywords: collective unconsciousness; self; soul; Wordsworth

\section{Introduction}

William Wordsworth (1770-1850), one of the most important poets of the $19^{\text {th }}$ century in English literary history, is the famous Lake poet who spends most of his life in isolation for writing. In the early period of French Revolution, Wordsworth was active and radical; however, the following shift of Revolution shook him violently, which brought him to contemplate on the historical events, human lot even to cosmos. After a long interval, it became apparent that new life and new hope came up with him. The turning point was in 1798, he settled down in the famous Lake District in England to look to poetry to show his value of life and of cosmos.

Witnessing the French Revolution and industrialization, Wordsworth exerted on a balance between spirit and material, self and world; and on searching for the solvation from the side effect of The Revolution. From Jung's psychoanalysis, the mainstream of the collective culture being torn apart, the primitive psyche has been lost. Soul as an element of collective unconscious manifests itself in primitive archetype that enable us to penetrate into the deeper, creative levels of human potential, without being destroyed by it. Soul presents itself in the Universe, in humankind and in nature; in individual and the world. Wordsworth lays stress on mind, psychology and society which all be shown in his poems. His general psychological observation, and his social and political concerns, which constituted his Returning complex: returning to soul.

The personal unconscious and the collective unconscious make the returning possible. The paper firstly deals with the relationship between the individual soul and the world soul. Self is the core of soul combining the individual soul with the world soul. Returning to Self can evoke individual a sense of unity. Secondly, Wordsworth's outlook on nature and human manifests the great love of Self. In Wordsworth's poetry, particularly for the nature poem, he depicts the way that nature is in one with humankind; therefore, love of nature leading to love of humankind is the process of Self-emergence, and the individual soul uprights to the World soul when great love coexists with selfless identity. Briefly, returning to Self leads to the consistency of soul, also the grand harmonious individual with community, world and cosmos. 


\section{Theory: The Individual Soul and The World Soul}

The ancient maxim "know thyself" has come to mean "turn inward and away from the world" self-knowledge, however, actually means knowing, experiencing, feeling, sensing the world fully. We know ourselves through the world, and the world is reshaped with human self-knowledge. In the light of analytical psychology, the soul of individuality inevitably takes us into the soul of the world; the two are inseparable, Since individuality is not something that is completed but is coming to be, the ability to have an inner sense of the inner qualities of outer things as existing in relation with one another, is Self.

The depth of psychology cannot effectively divide soul from world because they are not two totally separate realms. This binding factor is Self. Gothe expressed a similar goal for humanity: "when a man's healthy nature works as a whole, when he feels himself to be living in the world as in a great, beautiful and worthy whole, when his harmony brings him a pure, free joy, then the universe, if it could come to be aware of its own self, would cry out in exultation at having reached its goal and would marvel at the height which its own being and becoming had attained."(Robert Sardello, 2008)Here Wordsworth finds a spiritual ideal that is not founded on self-renunciation, turning away from the world, in fact, developing the sense of the Self is at the same time coming into a new kind of relationship with the world. Jung generally did not refer to personality but rather to the psyche, a Latin word that originally meant, "Spirit" or "soul". Jung referred to the total, integrated personality as the Self, including all of a person's qualities and potentials. He elaborates in the context of the sense of the Self, what is encompassed by the word "world". He means something different from our ordinary sense of the physical world, the Earth, and also something different from the combination of the earth. With its plant, animal, and human life, and all that has been developed in this place of Earth by human hands----that is culture and civilization. World will be used here always to mean the unity of relationships between plant, animal, and human being on the one hand, and Earth and cosmos on the other, not just in an external way, but according to the shared characteristic of soul.

A central picturing the development of the sense of "I," and the intimate relation between the" I" and the soul of the world, which means everything would be in harmony. Every part of the world would function as part of the whole. With the ability to have an inner sense of the inner qualities in the outer things as existing in relation with one another, the capacity of Self is first a receptive quality of love, then a Void of selfhood when sensing unity. This must be actively taken up in production of images reflecting this unity that can be expressed by the art.

Wordsworth's Self consists in any power of elaborating what is usually understood in the Universe: in contemplatively seizing the characteristic individual mingled with all living things, form the very smallest of earth and the Spirit of cosmos, and radiates around them to every mind that will surrender itself to their expressive power. Wordsworth chiefly did not paint nature, but arrested and interpreted the spiritual expression. In other words, the tacit communication between nature and human implicates the kinship between them. There is no one among English romantics but Wordsworth who has led us to sense the eternal light of an infinite Self in equilibrium by surveying the alteration of season, the evolving rule, the vicissitude of nature illuminated soul's power. In "To the Cuckoo: he welcomes, " darling of the spring" but to the poet, "No bird, but an invisible thing,/ a voice, a mystery;" he roves through woods and on the green to seek it with a hope, a love," he spiritualized into a 'wandering voice,' that tallest unto me a tale of visionary hours," (Geoffrey H. Hartman, 2007) the mountain echoes, which sends her "unsolicited reply' to the same babbling wanderer; he can't help exclaiming, with his gentle touch, for there is a spirit in the woods, the abstract image represented archetypes of being by the poet's insightful lines which brought us to conscious aspiration, love and spiritual longing, to imagine the full depth of human heart with common sense of the inexhaustible wealth of Nature's symbols. In another poem To Daisy: Wordsworth honors the Daisy's humility, affirming that the daisy lives with less ambitious aim than "violets in their secret news" and the proud rose "With rains and dews/ her head impearling", the poet declares:

If stately passions in me burn,

And one chance look to Thee should turn,

I drink out of a humbler urn

A lowlier pleasure;

The homely sympathy that heeds

The wisdom fitted to the needs

Of hearts at leisure (Geoffrey H. Hartman, 2007)

The humility and his goodness evolving from the nature of things themselves, from the conditions of his own 
existence, what is so appealing about the humility of daisy is its ordinariness. It carries with it the sense of being perfectly natural and unaffected, of a simplicity that "something in common with naivety which is the perfect reflection of unselfconscious emptiness at the heart of one's being"( Zhang Xuchun,2000). Wordsworth's persona exhibited no sense of spiritual distinction: the mind is perfectly natural, in the human or the social. So the daisy's ministry flows, from the very processes of nature itself and not from any false or artificial sense of its own emptiness, to let things speak from the depths of one's own nature, hence the ambient selflessness evoked by charity is both a product and a reflection of an abiding unity at the heart of all things.

Whereas to most men the material world is a heavy gross, Wordsworth felt a living, breathing power, and full of life; the Cumberlanad beggar, the ruined cottage, or the furious movement and the city in decaying which constitute the flowing civilization all express their suffering, sensation, and thought, what they occupied are surrounded with what conceals the sameness of soul as the main current. An epoch is like an individual; it has its own limitations of conscious, and therefore requires a compensatory adjustment for unconscious in order to recall the coherence of soul. His eye almost saw into it, he said, "I was often unable to think of external things as having external existence, and I communed with all I saw as something, not apart from, but inherent in my own immaterial nature". That's the point of Self-emergence makes him feel as broadly and profoundly the vast life that is in nature, in outer world has bridged over the gulf between subject and object, "self" and "other". These boundaries are not necessarily perceived but might have been created by the human mind as a way of keeping things orderly. Desire deprives people of the sense of community--- not only the community between men, but in its wider aspects ----- a spiritual community that Wordsworth had himself perceived. Though the intimacy of love, all of the things of the world become radiant, shining, and alive so the Earth as a whole becomes the Earth Sun. The individual soul and the World Soul do not exist as opposition, but as interpenetrating reality, as to attain virtually a grand harmony.

\section{Love of Nature Leads to Love of Humankind}

In his poems Wordsworth proved that all kinds of things especial for nature are not solitary images excluding from human being, but presents itself as a holograph of world. His poetic undertaking is grounded in culturally rich confrontation between the world and the individual self. Since individual soul integrates with World soul, Self can realize itself in the World.

One of the capacities of Self is a receptive quality of love, hence all the manifold and different phenomena of the Self are modifications and various transformations of love. There was in fact a current meaning of love available to Wordsworth. Fraternity for nature and for humankind that offers a perception of mind and world as a vital continuum, as a basic identity or unity beyond hermeneutic impulses to find meanings, to interpret the world with a subject-object dichotomy, thereby separating man from his world. Many of Wordsworth's poems record a progressive journey leading to a higher or more integrated relationship between the "I" and the world. "Love of nature thus leads to love of humankind "not through a narrative progression from one state of being to another but through a poetic process that entails the falling away of layers of distinction between one thing and another.

The Morning light/loves as it glistens on the silent rocks, / and them the silent rocks, which now from high/look down upon them; the reposing Clouds/ the lurking Brooks from their invisible haunts. (Geoffrey H. Hartman, 2007)Beings in nature share the same feeling with human, the whole-length figure of nature is not from the poet's imagination or his personality acting on it, but deriving from the projection of Self (Karl Jung, 2002): In a state of Self presentation, feeling emanating from all things can communicate with each other to show the equality and fraternity. Through the individual's recognition that love of nature is love of humankind: the resulting perception of human unity, like the conscious love attributed to mountains, rocks, and morning light, is of the nature of reality. The poet frequently sees this state as a condition of harmony with the World soul or the Tao: the universe and the source of life, the undifferentiated, neither "Self" nor "other".

The growth of this dependent human love is seen in The Prelude to run through stages. "the ' filial bond' of child and mother... establishes the larger bond of man and Nature..." Sometimes in late adolescence one can expect to experience the latter bond as "A dawning, even as of another sense,/ A human-heartedness about my love/ For objects hitherto the gladsome air/ Of my own private being, and no more"(Wordsworth,2004).

Love occurring in Wordsworth's poetry exists in greater simplicity and strength to combine nature with human, while Wordsworth did go through what is often called a pantheistic period, nature was seen even then as but a means toward something greater. To seek origin as a cause beyond one, that is to seek it outside the dimensions of the mind, is like trying to see the very eye by which one perceives. In The prelude Wordsworth wrote: 
From Love, for her,/ Do we begin and end,/ And grandeur comes,/ All truth and beaut,/Form pervading love,/ That gone, we are as dust./... There is higher love,/ Than this a love that,/ Comes into the heart with we and a diffusive sentiment; / Thy love is human merely; this proceeds/More from the brooding soul, and is divine.

The community of spiritual love may expand beyond the human heart, in abundance of poems, Wordsworth attempts to express the ideas conveying the binding of the individual soul with the world soul. Sufficient instances of natural love in animals, of bonds between creatures, accumulate to make a case. As in "Tintern Abbey" the pantheism of the middle lines above shades off into a more orthodox personal God, who sympathizes, cares, and loves, and who is part of what could be called the Cosmic Community. The Self is awaken to the sense of the world as soul experiences the whole cosmic, natural, and human world is the true self hidden in inmost, through whom one finds the perfect reflection of his soul.

Self is the reality making the soul's inner unity fully possible. The poet retains, not a mind that seeks for anything beyond itself, but one that accepts freely, that opens to the impulses of nature---- to the shining of the moon, to the play of misty mountain-winds. It is a mind that will persist as a "mansion for all lovely forms" and whose memory will be "as a dwelling-place/ For all sweet sounds and harmonies" (Wordsworth, 2004). If animal seems to be entering the membership of the human community, inanimate creation tends to take on the life and sensation of the animal community. Such a view is known as animism. The Greek maxim that the human being is a microcosm reflecting the whole macrocosm finds its modern expression in the notion of amity, in a sense, Wordsworth deduces the theory with his poems, transferring it into the community of spiritual love: psychologically it is the Self exerts itself on soul' function. Plant, animal, all kinds of creatures are one in the world, each perform an act--- the act of inner, conscious awareness shaping, forming and interiorizing the essence of each moment of experience, endowing experience with love. Has been awakening to feel for all expressions of love, the poet frees himself spontaneously in the face of fountain rock, river, and lake. His poems imbued with the mysterious power that he had never found before. His work affirms a vital connection between the individual and the external world. Wordsworth evokes a powerful sense of the Self deeply conscious of sometimes preoccupied with, its own transforming and organizing energies, furthermore, to realize the unity of the world, to sense the community of love. The notion of "one spirit" helps us to figure out why Wordsworth employs such words as nature, soul, God and spirit in his poems. Being is apparently meant to be synonymous with life; clearly he maintains that fountains, rocks, and trees possess a powerful sense, presumably a reaching into community. In this way Self comes up as our facing the world, to identification of the world. The world is thus a truly thou. Another instance of how deeply animism appealed to Wordsworth occurs in a letter to Coleridge late the next year (Wordsworth, 2004): "Besides, am I fanciful when I would extend the obligation of gratitude to insensate things? May not a man have a salutary pleasure in doing something gratuitously for the sake of his house, as for an individual to which he owns so much." That the feeling linked with human and nature, and the moral life evoked the community of love. As late as 1829, the speaker in "humanity" describes the passing of the use of "Rocking-stones" for "judicial and religious purposes" and then comments:

For the initiate, rocks and whispering trees

Do still perform mysterious offices

And functions dwell in beast and bird that sway

The reasoning mind, or with the fancy play

Inviting, at all seasons, ears and eyes

To watch for under exclusive quarries:---

Not uninspired appear their simplest ways;

Their voices mount symbolical of praise---

To mix with hymns that Spirits make and hear;

And to fallen man their innocence is dear. (II 9-18)

Here the suggestive animism implies a kind of community in collective unconscious, uniting rocks, trees, beasts, birds, spirits, fallen man, and God. Love of nature, then, leads to love of humankind through the individual's recognition that love of nature is love of human kind. The poetry represents man in no isolation from nature.

"Most loving Soul!/Place on this earth to love and understand,/ and from their presence shed the light of love"(Wordworth, 2004) Furthermore, love of nature leads to love of mankind illuminated that the "Spirits " may portend an even wider human community, extending beyond time and space. The speaker exclaims: dealt and life, 
reality and thought, ego and God, to let alone the boundaries between the dualistic terms. In The Essay on Epitaphs Wordsworth writes of "a community of the living and the dead" that is a spiritual community binding together the living and the dead. In "the Bothers" that "The thought of death sits easy on the man who has been born and dies among the mountains"(II.182-183) He shared the view of a community overlapping life and death, and there was opportunity enough in the death of his relatives, his exalted Nature has not perished --- but, far better--- and they who remain on earth shall have them with us a perpetual presence. Wordsworth's "the Ruined Cottage," is particularly helpful here. The poem centers upon a young man's progress from restless agitation in the face of natural processes to a state of wisdom that enables him to see into the moving form of things and to accept as an end in it the deep tranquility at the heart of eternal change. It reflects the poet's growth in mind in the post-revolutionary period and gives the significance of life and death, lost and gain to the very full. In this poem, the peddler was lost in sadness, encountering the abandoned cottage open to the sky. Suddenly he was attracted by an old man's "easy cheerfulness"--- a manner that, paradoxically, both draws upon and deflates the solemnity of his tone while conveying, as well as a deep warmth contrasts sharply with the " heartfelt chillness". The old man embodies the Wise man ( is opposite to the Great Mother in analytical psychology ) with complete soul, the heroine's death hints human suffering which is the natural law, and The young man is the epitome of humankind seeking for soul and unfolding Self. By the old man's guidance the compassion aroused in him and kindred birth sympathies to the heroine, the peddler seeks to make available to his inner nature, it is the meaning of love above life and death, and unoccupied by feeling of his own, his heart lay open being that his understanding of access to such "Mind" or "True-nature", accrues through the process of laying conscious to rest and viewing the fraternity of existence from the depths of a powerful and abiding peacefulness.

Love for humankind is obviously put forth in the political sonnets after the failure of French Revolution, he appeals for Milton with enthusiasm; England is in great need of the ancient power of inward happiness. "Raise us up, return to us again, and give us manners, virtue, freedom, power."(Geoffrey Hartman, 2007) Milton symbols the vanishing England Soul that was like a star and dwelt apart. The love that mingled with anxiety for homeland and recollection for the ancient spirit act on another poem: England! The Time Is come composed in 1803, "the wise pray for thee, though the freight/ Oh grief that Earth's best hopes rest all with Thee". Spiritualizing power shed over love for nature and for mankind fixes his attention not only on nature that represents the archetype of life origin, but on his company and his epoch that restored the World soul, so the outer world extends from nature to social community, and love is elaborated at length to awaken Self.

For Wordsworth's view of the Self at work in his poem, the unity of all had been revealed, and that unity shows up concretely in Wordsworth's social psychology. Wordsworth was concerned to dissolve such boundaries created between the inanimate and animate, the animal and human, and finally between the living and dead. That's the glory of Self according to Jung, " from love,/ for here/ do we begin and end, all grandeur comes/ all truth and beauty, from pervading love"(Wordsworth, 2004) All things have necessarily followed for the given nature of soul therefore to love for Beings gives itself a full play in the Self.

The modern American critic John Rudy holds the view that another capacity attached to Love for The Self is void of selfhood. The Self is not a conception solely owned by human. He refers to this formless interior self as the Great Self. All modes of selfhood consist of the temporary formal individual. Our true Self is the Great Self, who beyond good and evil, serene, deathless, and self-sufficing, with the same nature and root as the universe itself. (John G. Rudy, 1996)Wordsworth could not have experienced his journey as anything other than an "endless way," that is, from the individual self to the eternity of a "heavenly destiny," the motionless motion of the non-self which forms the dimensionless source or ground of being at all times.

\section{Conclusion}

Self as the center of soul contains conscious and unconscious elements is considered to result only from individuation of the soul that comes from the inner work. It constructs the personality as a whole so as to maintain soul entity and combines the individual soul with the World soul closely. To be a "living soul" in this sense is to be one with a world in which all things are in motion and inter-animate with all other things. To see into the life of things so construed is to be the life of the very things one may perceive initially as Self.

In the light of spirit, Wordsworth articulated the capaciousness through the recognition of love to express Self by the common feeling in the Universe, which concretes Self in reference to the emptiness perceived as the absence of selfhood. Thus the life of all things and the mighty unity in all which human behold are the individual soul uprights to the World soul when broad love coexists with selfless identity. In a word, returning to Self leads to the consistency 
of soul, a balance between the conscious and the unconscious, also to the grand harmony individual with community, world and cosmos.

Psychology throws light on that soul reveals a wholeness and a balance self. Wordsworth sets forth that the vital thing that human needs to grasp in his life is not in his realization by seeking for the outer world but to maintain the consistency and unity to the inner world. Briefly, it is an internalization of soul-questing. The process of self-awakening most visibly in poems that show the poet on a path or journey, the journey motif represents a perilous quest in search of vocational responsibility to spiritual renewal. Soul that finds rootedness in archetypes and culture is in these instances holing fast to primary reflections of itself as creative both of the universe and of the human world, the latter that has a special significance in relation to the whole. Wordsworth's poems recorded his own experience--- the growth of mind, also recorded his unswerving exploiting on the function in psychic integration--how it influences the crystallization of the individual identity and the formation of soul. The poet deals with the structure of soul and insights into the core of it: that is Self. To return to Self enhances the relationship of the individual with the world since one is a part of the world. The integrated, total Self can be self-evidence in discarding the difference between "I" and "it"so as to prove the wholeness of the individual soul and the world soul. The capacity of Self shows the cosmic community of love in the void of selfhood. That's the peak of the Great Self being one with the world.

\section{Acknowledgments}

The paper is subsidized by Foundation called "YOUTH SOCAIL SCIENCES PROJECT" as one of the research projects of Henan Social and Scientific Association, Jiaozuo. Special thanks are given to the Project Foundation and Henan Polytechnic University

\section{References}

Ernest de Selincourt. (1978). The letter of William and Dorothey: The Middle Years, Part II. In Eds. MaryMoorman and Alan G.Hill. Oxford: Oxford University Press.

Geoffrey Hartman, ed. (2007). The Selected Poetry and Prose of Wordsworth. Oxford: Norton, W. W. \& Company, Inc.

John G. Rudy. (1996). Wordsworth and the Zen Mind. New York: State University of New York Press.

Karl. Jung tran. Li Derong. (2002). Psycho-Analysis. Beijing, China: Jiuzhou Publisher.

Robert Sardello. (2008). Love and the Soul: Creating a future for Earth. Harper Perennial Collins Publishers.

William Wordsworth. (2004). The Prelude (1805). Oxford: Oxford University Press.

Zhang Xuchun. (2000). The Political Aesthetics and Aesthetical Politics. Beijing: People's Press. 